\title{
$\mathrm{La}_{7} \mathrm{Os}_{4} \mathrm{C}_{9}$ 의 전자구조와 화학결합
}

\author{
강 대 복* \\ 경성대학교 화학과 \\ (2009.5.1 접수)
}

\section{Electronic Structure and Chemical Bonding of $\mathrm{La}_{7} \mathrm{O}_{4} \mathrm{C}_{9}$ \\ Dae-Bok Kang* \\ Department of Chemistry, Kinthgsung University, Busan 608-736, Korea}

(Received May 1, 2009)

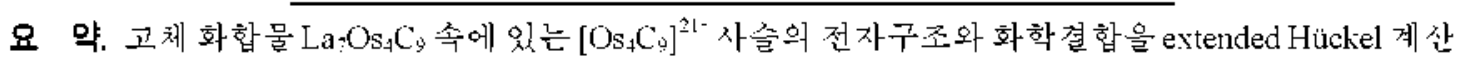
결과에 의해서 논의하였다. 탄소 원자는 물론 $\left(\mathrm{C}_{2}\right)^{2-}$ 분자의 결합 특성온 비교적 콘 $\mathrm{Os}-\mathrm{C}$ 상호작용을 나 타내었고 특히 $\left(\mathrm{C}_{2}\right)^{2-}$ 분자의 결 합길이 증가는 Fermi level 바로 아래에 $\mathrm{Os}_{\mathrm{s}} \mathrm{C}_{2}\left(\mathrm{l} \pi_{\mathrm{g}}\right)$ 결합 밴드의 존재로 인

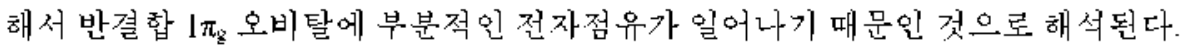

주제어: Ternary transition metal carbide, Electronic structure, Extended Hückel calculations, FMO analysis

\begin{abstract}
In the recently synthesized rare earth transition metal carbide $\mathrm{La}_{-} \mathrm{Os}_{4} \mathrm{C}_{9}$ one finds one-dimensional organometallic $\left[\mathrm{Os}_{+} \mathrm{Co}_{0}\right]^{21-}$ polymers embedded in a $\mathrm{La}^{3+}$ ionic matrix. The electronic structure of the polymeric $\left[\mathrm{OS}_{+} \mathrm{C}_{0}\right]^{21-}$ chain was investigated by density of states (DOS) and crystal orbital overlap population (COOP), using the extended Hückel algoritlun. A fragment molecular orbital analysis is used to study the bonding characteristics of the $\mathrm{C}_{2}$ units in La-OS $\mathrm{C}_{4}$ containing $\mathrm{C}_{2}$ units and single $\mathrm{C}$ atoms as well. The title compound contains partially filled $O$ s and carbon bands leading to metallic conductivity. As the observed distances already indicated, the calculations show extensive $\mathrm{Os}-\mathrm{C}$ interactions. The $\mathrm{C}-\mathrm{C}$ bond distance in the diatomic $C_{2}$ units $\left(d_{c}=131 \mathrm{pm}\right)$ in the solid is significantly increased relative to $C_{2}{ }^{2-}$ or acetylene, because antibonding $1 \pi_{\mathrm{g}}$ orbitals are partially filled by the $\mathrm{Os}-\mathrm{C}_{\mathfrak{z}}\left(1 \pi_{\mathrm{g}}\right)$ bonding contribution found at and below the Ferni level.
\end{abstract}

Keywonls: Temary transition metal carbide, Electronic structure, Extended Hückel calculations, FMO analy sis

\section{INTRODUCTION}

A large number of ternary carbides of the rare earth elements with transition metals have been synthesized in the recent years. ${ }^{1-5}$ The rare earth element in these temary systems is a highly electropositive multivalent metal. Complete ionization of the electropositive metal leads to a transition metal-carbon polyanionic substructure where the carbon atoms are more or less covalently bonded to the transition metal atoms. frequently forming organometallic polymers. These compounds exhibit structural diversity. containing isolated carbon atoms. $C_{2}$ pairs and $C_{s}$ units. One also finds in them interesting metal-carbon networks of varying dimensionality.

In this paper. we turn our attention to a new one-dimensional organometallic polymer in the temary compound $\mathrm{La}_{5} \mathrm{Os}_{4} \mathrm{C}_{9}$ with mixed carbon ligand types. synthesized by Wagner and Kniep. ${ }^{1}$ Two types of $C_{n}(n=1.2)$ units are present in the structure, yielding the unit cell composition 
$\mathrm{La}-\mathrm{Os}_{4}\left(\mathrm{C}_{2}\right)_{2} \mathrm{C}_{5}$. The Os-C shects have two types of carbon atoms, each bridging two Os atoms in either a linear or a bent geometry and the $C_{z}$ pairs occupying terminal positions.

The elcctronic structure of this compound is studied with the results of extended Huckel tightbinding (EHTB) calculations. ${ }^{*}$ The exponent (C) and the valence sliell ionization potential $\left(H_{u}\right.$ in cV) were respectively used in the molecular and tight-binding calculations as follows: 1.625. -21.4 for C 2 s: $1.625,-11.4$ for C $2 \mathrm{p}: 2.452,-8.17$ for $O s$ 6s: $2.429 .-4.81$ for Os 6p: $2.14 .-7.67$ for La 6s: $2.08,-5.0 \mathrm{~L}$ for $\mathrm{La} 6 \mathrm{p} . \mathrm{H}_{\mathrm{n}}$ values for Os $5 \mathrm{~d}$ and $\mathrm{La}$ $5 \mathrm{~d}$ were set equal $10-11.8+$ and $-8.21 \mathrm{eV}$. respectively. A linear combination of two Slater-type

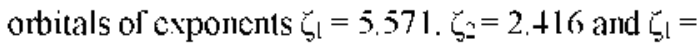
3.78. $\varsigma_{2}=1.381$ with weighting coefficients $\mathrm{c}_{1}=$ $0.6372, c_{2}=0.5598$ and $c_{1}=0.7765, c_{2}=0.4586$ was used to represent the $5 \mathrm{~d}$ atomic orbitals of $O \mathrm{~s}$ and La, respectively: The crystal structure of $\mathrm{La}_{-} \mathrm{Os}_{4} \mathrm{C}_{9}$ was used for the calculations. The sclected bond lengths and angles lisled in Tahle 1 . Sets of $396 \mathrm{k}$ points chosen in the corresponding irreducible Brillouin zone were utilized for the calculations of the density of states. crystal orbital overlap populations. and atomic net clarges. A fragment molecular orbital (FMO) anily sis is used to gain information about the bonding interactions of the $C_{2}$ units. In electronic structure calculations the interactions between atoms can be examined by density of states (DOS) and crystal orbital overlap population (COOP). The COOP can be looked upon as the DOS weighted by the overlap integral $S_{\| !}$betwoen two chemical species $\mathrm{i}$ and $\mathrm{j}$.

Table 1. Selected bond lengths (pm) and angles (deg) for $\mathrm{I}_{\mathrm{ar}} \mathrm{Os}+\mathrm{C}_{4}$

\begin{tabular}{lrlr}
\hline \hline Osl-C2 & 194.3 & Osl-C:l & 196.7 \\
Os1-C1 & 207.4 & Os2-C5 & 192.3 \\
Os2-C3 & 192.9 & Os2-C.2 & 193.0 \\
Osl-Osl & 271.6 & $\mathrm{C} 3-\mathrm{C} 4$ & 131.6 \\
Osl-C.1-Os1 & 84.4 & $\mathrm{C} 1-\mathrm{Os} 1-\mathrm{C} 1$ & 95.6 \\
$\mathrm{C} 1-\mathrm{Os} 1-\mathrm{C} 2$ & 150.9 & $\mathrm{Cl}-\mathrm{Os} 1-\mathrm{C} 2$ & 113.5 \\
Osl-C2-Os2 & 172.9 & $\mathrm{C} 2-\mathrm{Os} 2-\mathrm{C} 3$ & 119.4 \\
$\mathrm{C} 2-\mathrm{Os} 2-\mathrm{Cs}$ & 114.8 & $\mathrm{Os} 2-\mathrm{C} 3-\mathrm{C} 4$ & 162.9 \\
\hline
\end{tabular}

In the plots. positive and negative magnitudes of COOP are indicative of bonding and antibonding interactions. respectively.

\section{RESULTS AND DISCUSSION}

\section{Crystal structure}

The title compound crystallizes in the monoclinic space group $\mathrm{C} 2 / \mathrm{m}$ with wo fornula units $\mathrm{per}$ cell. ${ }^{l}$ The crystal sinucture of $\mathrm{La}_{-} \mathrm{OS}_{4} \mathrm{C}_{9}$ is shown in Figtire 1. Quasi-one-dimensional polymers of stoichiometric Os $\mathrm{C}_{4}$ are well separated in the lattice. The polymeric structure comprises covalent chains of $\left[\mathrm{OS}_{1}\left(\mathrm{C}_{2}\right)_{2} \mathrm{C}_{5}\right]^{2 l-}$ extended along the cry stallographic $c$ axis with $\mathrm{La}^{31}$ ions in between. All the atoms along the chain are in the same plane. Two types of carbon species, bridging $\mathrm{C}$ atoms and terminal $C_{2}$ pairs are clearly distinguishable. Both are situated in distorted metal octahedra.

The poly meric anions are composed of altemating $\mathrm{Os}\left(\mathrm{C}_{2}\right) \mathrm{C}_{2}$ and $\mathrm{OsC}_{\mathrm{i}}$ units with osmium atoms in distorted trigonal planar coordination (Figure 1). OsI has threc $C$ ncighbors at distances covering the range from $19+$ to $207 \mathrm{pm}$. Two of them form $\mathrm{Os}_{2} \mathrm{C}_{4}$ [ragments with an Os-Os dislance of 272 pm (270 pm in elemental Os) via the common

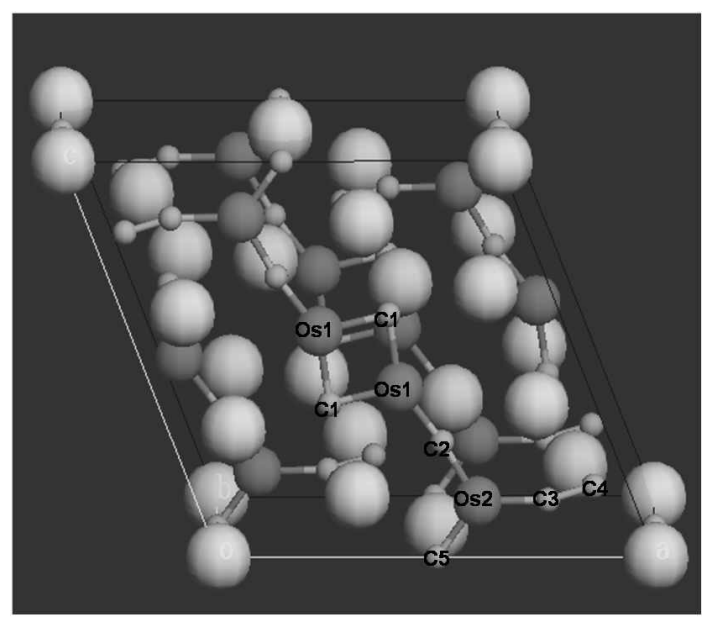

lig. 1. Unit cell of the monoclinic $\mathrm{La}_{2} \mathrm{O}_{4} \mathrm{C}_{4}$ striclure. The lanilhanum, osmim, and carbon atoms are drawn as large, medium, and snall circles, respectively. the

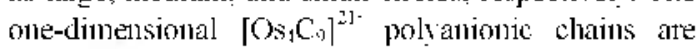
emplrasized. 
C...C edge. The Os2 atoms are surrounded by two $C$ atoms and one end-on $C_{2}$ pair at the rather short distance of about $193 \mathrm{pm}$. The sum of the covalent radii of osmium and carbon is $203 \mathrm{pm}^{9}$ Hence the average Os-C bond distance of $196 \mathrm{pm}$ is somewhat shorter than that expected for a single bond. We thus ascribe some double bond character to the Os-C bonding interactions. The angles $\mathrm{C}-\mathrm{Os} \mathrm{I}-\mathrm{C}$ within the $\mathrm{OsC}_{3}$ unit range between $95.61^{\circ}$ and $150.81^{\circ}$ and the angles $\mathrm{C}-\mathrm{Os} 2-\mathrm{C}$ in the $\mathrm{Os}\left(\mathrm{C}_{2}\right) \mathrm{C}_{2}$ unit between $114.91^{\circ}$ and $125.81^{\circ}$. The $\mathrm{C}_{2}$ pairs display a $\mathrm{C}-\mathrm{C}$ bond distance of 131 $\mathrm{pm}$. This value is slightly larger than the carboncarbon triple bond length in acetylene $(121 \mathrm{pm})$. suggesting an intermediate bonding situation between a $\mathrm{C}-\mathrm{C}$ triple bond and a double bond ( 134 pm). This ligand may be considered to be the dinegative $\left(\mathrm{C}_{2}\right)^{3-}$ derived from the deprotonation of a vinylidene ligand $\mathrm{H}_{2} \mathrm{C}=\mathrm{C}=\mathrm{M}$.

The $\mathrm{La}$ atoms are surrounded in a distorted square planar. tetrahedral and trigonal bipyrramidal way by carbon atoms at separations ranging from 263 to $282 \mathrm{pm}$. These distances are all slightly longer than the metallic radius of lanthanum ( 169 $\mathrm{pm}$ ) and the single-bond radius of carbon (77 pm) which add up to $246 \mathrm{pm}$. The La atoms have La neighbors at distances between 348 and $390 \mathrm{pm}$. while the $O$ s atoms have La neighbors at distances between 314 and 332 pm. These distances are very similar to the sum of the metallic radii of 374 pm for La-La and $322 \mathrm{pm}$ for La-Os. Although the $\mathrm{La}-\mathrm{C}$ and $\mathrm{La}-\mathrm{Os}$ interactions at these distances are not negligible, the Os-C interactions are certainly most significant. All interatomic distances are comparable to those found in the crystal structure of $\mathrm{La}_{5} \mathrm{O}_{3} \mathrm{C}_{4 \cdot x}$.

Calculations on the entire three-dimensional $\mathrm{O}_{4} \mathrm{C}_{9}$ sublattice in $\mathrm{La}: \mathrm{O}_{4} \mathrm{C}_{9}$ and on the whole crystal lattice of $\mathrm{La}_{2} \mathrm{O}_{4} \mathrm{C}_{9}$ result in similar $\mathrm{DOS}$ curves. The COOP calculations on the latter indicate that the $\mathrm{La}-\mathrm{C}(\mathrm{OP}=0.18)$ and $\mathrm{La}-\mathrm{Os}(\mathrm{OP}=0.09)$ interactions are much weaker than the Os-C $(\mathrm{OP}=$ $0.67)$ ones. The fact that covalent bonding of Os-C bonds is stronger compared with $\mathrm{La}-\mathrm{C}$ ones forms the basis for separating the complex carbometalate anion from the La substructure. Furthenmore. even though $\mathrm{La}-\mathrm{C}$ interactions reveal a significant covalent character, the oxidation states of the La atoms have to be considered as +3 since no $\mathrm{La}$ majority band states are occupied below the Fermi level. This gives us confidence that the formula of this compound can, to a first approximation. be written as $\mathrm{La}^{3+}\left[\mathrm{Os}_{4} \mathrm{C}_{9}\right]^{31-}$, emphasizing the covalent Os-C bonding in the polyanionic units.

\section{Electronic structure of polymeric $[\mathrm{Os} 4 \mathrm{C9}]^{21-}$ chains}

As outlined above. the chemical bonding in the $\mathrm{La}: \mathrm{Os}_{4} \mathrm{C}_{9}$ carbide can be rationalized by simple electron counting, assuning complete charge transfer of all valence electrons of the lanthanum atoms to the $\left[\mathrm{Os}_{4} \mathrm{C}_{9}\right]$ moieties. We first consider a molecular model. $\left[\mathrm{OsC}_{3}\right]^{1] \text {. }}$. in a trigonal planar coordination geometry with $\mathrm{D}_{3 \mathrm{~h}}$ synmetry. Figure 2 shows schematically how the orbitals on Os atoms interact with those on carbon ligands. Since carbon $2 s$ orbitals are very low in energy, and $O s 6$ p orbitals are high up in energy, both contribute little to Os-C bonding. Our parameters place the $O s 5 \mathrm{~d}$ orbitals just below the carbon $2 \mathrm{p}$ orbitals and the Os $6 \mathrm{~s}$ orbital above the carbon $2 \mathrm{p}$ orbitals. The major bonding interactions occur between carbon $2 \mathrm{p}$ orbitals and Os $5 \mathrm{~d}$ orbitals. At the bottom of the diagram we find five $\mathrm{Os} 5 \mathrm{~d}$ orbitals to form five Os-C bonding orbitals with symmetry-adapted con-

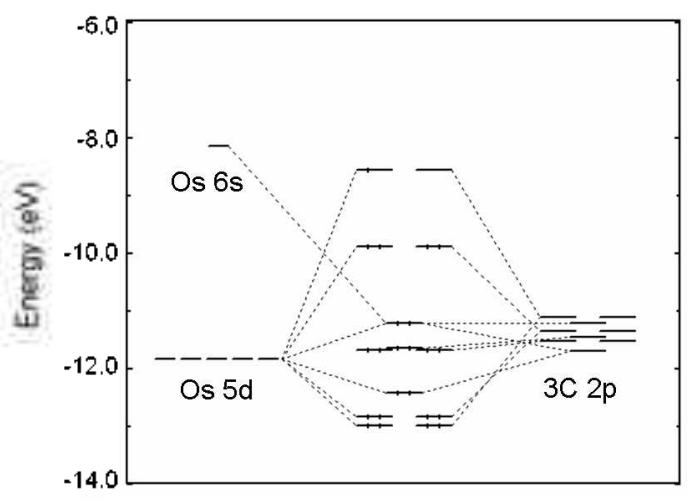

Fig. 2. MO diagram for the model compound $\left[\mathrm{OSC}_{3}\right]^{[1}$. in a trigonal planar geometry with $\mathrm{D}_{3 \mathrm{l}}$ słmmetry. All Os-C bond lengths are set to $196 \mathrm{pm}$. 
binations from the carbon ligands. There should be five Os-C antibonding orbitals at the top of the diagram. We only see four of them. The missing one should involve the Os $5 \mathrm{dz} z^{2}$ orbital; however. mixing in of the Os 6 s orbital in a bonding way turns this $\mathrm{Os}-\mathrm{C}$ antibonding combination into an essentially Os-C nonbonding orbital. located just above the five Os-C bonding orbitals. In the middle of the energy diagram. four carbon-based nonbonding orbitals are located.

It is useful to have some knowledge of the electronic structure of an isolated $C_{2}$ entity, which plays a crucial role in the solid. A $C_{2}$ molecule with a bond length of $131 \mathrm{pm}$ has the molecular orbitals of a typical homonuclear diatomic. Mixing of the $2 \mathrm{~s}$ and one $2 \mathrm{p}$ atomic orbitals (AOs) leads to four $\sigma$-type molecular orbitals (MOs): one strongly bonding $\left(2 \sigma_{g}\right)$. two nonbonding combinations $\left(2 \sigma_{1}\right.$ and $3 \sigma_{q}$ ). and one strongly antibonding $\left(3 \sigma_{u}\right)$. very high in energy. The other $2 p$ orbitals form pairs of degenerate bonding $1 \pi_{u}$ and antibonding $1 \pi_{\mathrm{g}}$ MOs. The energy levels of these orbitals are shown in Figure 3. The large gap computed between the nonbonding $3 \sigma_{\mathrm{g}}$ and antibonding $1 \pi_{\mathrm{g}}$ MOs ( $3.02 \mathrm{eV})$ would lead us to assign a count of 10 electrons for the isolated $C_{2}$ pairs. Note that the triple-bond character is retained for the formal charge of 2- per $\mathrm{C}_{2}$.

Figure 3 displays the $\mathrm{C}_{12}(\mathrm{n}=1.2$ ) DOS contributlons to the total carbon sublattice of the $\mathrm{La}_{0}: \mathrm{OS}_{4} \mathrm{C}_{9}$ structure. In the case of the isolated $\mathrm{C}$ atom two

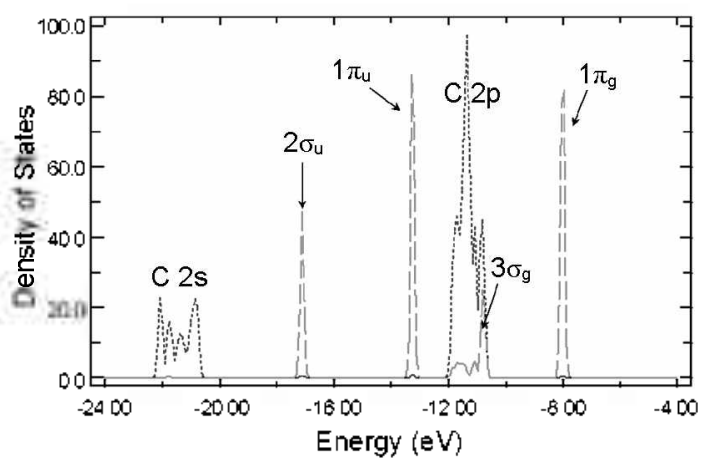

Fig. 3. DOS contributions of different carbon species $\mathrm{C}$ (dotted line, red) and $\mathrm{C}_{2}$ (dashed line, green) to the total carbon sublattice in the $\mathrm{La}_{7} \mathrm{O}_{4} \mathrm{C}_{9}$ structure. block bands corresponding to the $2 \mathrm{~s}$ and $2 \mathrm{p}$ levels of $\mathrm{C}$ are clearly seen centered around the relevant orbital energies of -21.4 and $-11 .+\mathrm{eV}$ as expected. For $\mathrm{C}^{4-}$ all levels would be filled; the Fermi level is located at $c a .10 .6 \mathrm{eV}$. The DOS contributions of the $C_{2}$ units to the total carbon DOS are consistent with the MO levels described above. The ordening of levels for $\mathrm{C}_{2}$. in the window shown in Figure 3 , is $2 \sigma_{\mathrm{u}}, 1 \pi_{\mathrm{u}} 3 \sigma_{\mathrm{g}}$ and $\mathrm{l} \pi_{\mathrm{g}}$ with increasing energy: For a formal charge of $\left(C_{2}\right)^{2-}$ the $3 \sigma_{g}$ band would be completely filled. with the Fermi level located at $c a-10.6 \mathrm{eV}$. If the electron occupations were $\left(C_{2}\right)^{+-}$, the antibonding $1 \pi_{a}$ states would be partially filled. Therefore, on the basis of the orbital occupations of $\mathrm{C}_{\text {and }} \mathrm{C}_{2}$ unuts, the charge distribution $\left.\left(\mathrm{La}^{3+}\right):\left(\mathrm{Os}^{015-5}\right)_{4}\left(\mathrm{C}_{2}^{2-}\right)\right)_{2}\left(\mathrm{C}^{4 \cdot}\right)_{5}$ constitutes a good oxidation state formalism to start with.

Covalent interactions between the Os atoms and the auonic entities must transfer somewhat of the anionic charge of the latter. The DOS plot for $\left[\mathrm{Os}_{4} \mathrm{C}_{9}\right]^{2 l-}$ is shown in Figure 4. along with the contribution of Os. bridging carbon atoms, and terminal $C_{2}$ pairs to the total DOS. The interactions between carbon and osmium result in strong orbital mixing. and thus the Os contribution is spread out over the whole energy range. indicating extensive Os-C bonding interactions. A decomposition of the contribution to the DOS of the dufferent elements

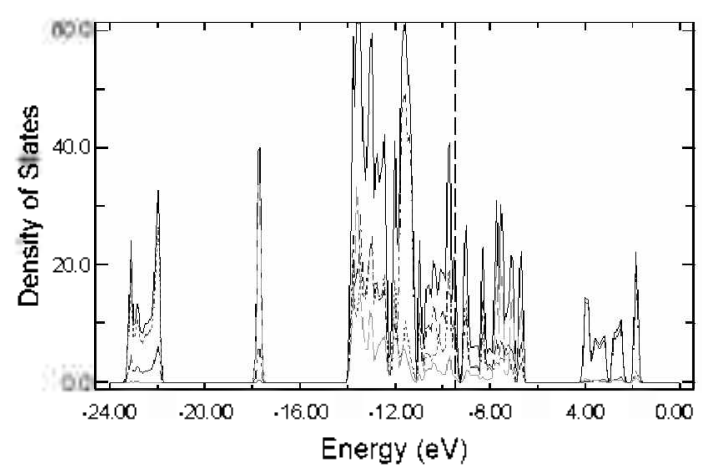

Fig. 4. Total DOS of the composite $\left[\mathrm{OS}_{4} \mathrm{C}_{4}\right]^{21-}$ structure assembled from the sublattices of carbon and $\mathrm{OS} . \mathrm{C}_{2} \mathrm{C}_{2}$, and $O$ s contributions to the total DOS (solid line, black) are marked by dotted (red), dashed (green), and dash-dot lines (blue), respectively. The dashed line at ca. $-9.49 \mathrm{eV}$ reters to the Femin level. 
indicates that the lowest part. centered at $-22.5 \mathrm{eV}$. derives mainly from the bridging carbon atoms. The projection on the $\mathrm{C}$ atoms indicates that most of the valence states of this atom are occupied, in agreement with its $\mathrm{C}^{4 \cdot}$ oxidation state. The $\mathrm{C}_{2} 2 \sigma_{1}$ and $1 \pi_{0}$ bands. centered at -17.8 and around -13.5 $\mathrm{eV}$, respectively, are pushed down in energy by the interaction with the Os d bands. The $3 \sigma_{\mathrm{g}}$ and 1 $\pi_{\mathrm{g}}$ orbitals. on the other hand interact strongly with the $O s \mathrm{~d}$ bands. spreading out over their energy range -12 to $-6.5 \mathrm{eV}$. The $3 \sigma_{\mathrm{g}}$ orbitals $(-12$ to $-\mathrm{Il} \mathrm{eV}$ ) are lowered. relative to the corresponding levels of the isolated $\mathrm{C}_{3}$. The important participation of $1 \pi_{g}$ orbitals is noticed at and just below the Fermi level $(-11$ to $-9 \mathrm{eV})$. although one finds states predominantly metallic in character. This portion is the $\mathrm{Os}-\mathrm{C}_{2}$ bonding (weakly $\mathrm{C}-\mathrm{C}$ antibonding) combination with the $\mathrm{Os}-\mathrm{C}_{2}$ antibonding combination ( $\mathrm{C}-\mathrm{C}$ antibonding) at higher energy, ranging from -8 to $-6.5 \mathrm{eV}$, which is composed mainly of 1 $\pi_{\mathrm{g}}$ orbitals. This is confirmed by the $\mathrm{C}_{2}$ COOP curve represented in Figure 5, which shows that $C_{\beth}$ antibonding $1 \pi_{\mathrm{g}}$ states are partially occupied near the Fermi level after interaction with the metallic host. Partial electron occupation of the low-lying $\mathrm{Os}_{-}-\mathrm{C}_{-}\left(1 \pi_{\mathrm{g}}\right)$ bonding states introduces a weakening to the $\mathrm{C}-\mathrm{C}$ bond. Consistent with this occupation. the $\mathrm{C}-\mathrm{C}$ bond length expands from the expected value for a $\mathrm{C}-\mathrm{C}$ triple bond of about $121 \mathrm{pm}$ to $131 \mathrm{pm}$. The $1 \pi_{g}$ levels of the $C_{z}$ unit are occupied

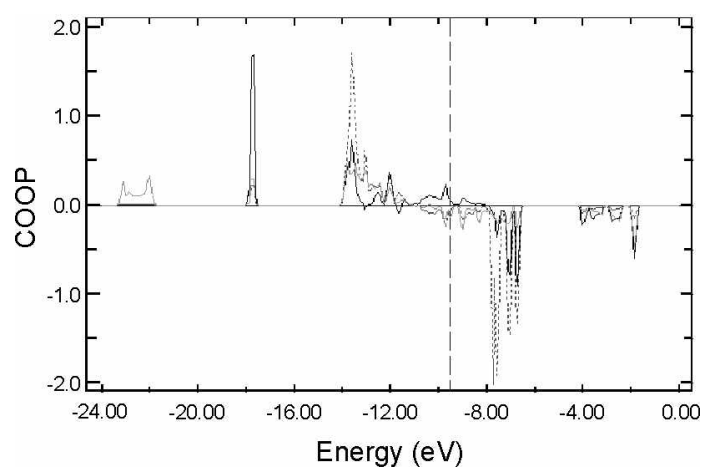

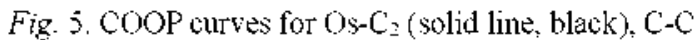
(dotted line, red), and $\mathrm{Os}-\mathrm{C}$ (dashed line, green) bonds in $\left[\mathrm{Os}_{4} \mathrm{C}_{0}\right]^{\hat{A l-}}$ structure. The dashed line at $\mathrm{co} .-9.49 \mathrm{eV}$ refers to the fermi level. in $\left[\mathrm{Os}_{4} \mathrm{C}_{s}\right]^{21-}$ by approximately 0.79 electrons. as obtained from an FMO analysis (see Table 2). For a triple bond in $\left(\mathrm{C}_{2}\right)^{2-}$ the MO levels are filled with 10 electrons up through the $3 \sigma_{\mathrm{g}}$ level. Introducing two more electrons would lead to a partial occupation of antibonding $1 \pi_{q}$ levels and thus a C-C double bond. The $1 \pi_{1}$ occupation of 0.79 in $\left[\mathrm{Os}_{4} \mathrm{C}_{9}\right]^{2]}$. leads to a $\mathrm{C}-\mathrm{C}$ bonding situation best described as an effective bond order between a double and a triple bond. The C-C overlap population, which is 1.74. calculated for the isolated $\left(C_{2}\right)^{2-}$ entity drops to 1.55 after interaction with the metallic host.

The calculated net atomic charges and FMO occupations are given in Table 2. The Mulliken population analysis gives net atomic charges of $\mathrm{Os}^{-1.69}$. bridging $\mathrm{C}^{-1.99}$. and terminal $\mathrm{C}_{2}^{-2.16}$. substantially different from their formal oxidation states. The atomic net charges reported in Table 2 reflect electron transfer from the $\mathrm{C}^{4 \cdot}$ toward the $\mathrm{Os}$ and from the $O$ s toward the $C_{2}$ units. These strong covalent interactions between the different elements in the solid manifest themselves also through the highly positive Os-C overlap population, which is 0.78 (Table 2). The COOP curves. given in Figure 5 . indicate that the $\mathrm{OS}-\mathrm{C}$ bonding is not maximized with some $\mathrm{Os}-\mathrm{C}$ antibonding states occupied. The Os-C COOP curve shows clearly the transition from the $\mathrm{Os}-\mathrm{C}$ bonding to antibonding region at

Table 2. Bonding characteristics computed for the $\left[\mathrm{OS}_{4} \mathrm{C}_{\mathrm{C}}\right]^{2 \mathrm{l} \cdot}$ structure

\begin{tabular}{lcc}
\hline \hline & {$\left[\mathrm{Os}_{4} \mathrm{C}_{9}\right]^{2]-}$} & $\left(\mathrm{C}_{2}\right)^{2-}$ \\
\hline Overlap populations: & & \\
Os-C & 0.78 & \\
Os- $\mathrm{C}_{2}$ & 0.86 & \\
$\mathrm{C}-\mathrm{C}$ & 1.55 & 1.74 \\
Os-Os & 0.07 & \\
Atomic net charges: & & \\
Os & -1.69 & \\
$\mathrm{C}_{2}$ & -2.16 & -2.00 \\
$\mathrm{C}$ & -1.99 & \\
FMO occupations: & & \\
$2 \sigma_{\mathrm{g}}$ & 1.97 & 2 \\
$2 \sigma_{u}$ & 1.82 & 2 \\
$1 \pi_{\mathrm{u}}$ & 3.94 & 4 \\
$3 \sigma_{\mathrm{q}}$ & 1.64 & 2 \\
$1 \pi_{\mathrm{s}}$ & 0.79 & 0 \\
\hline
\end{tabular}




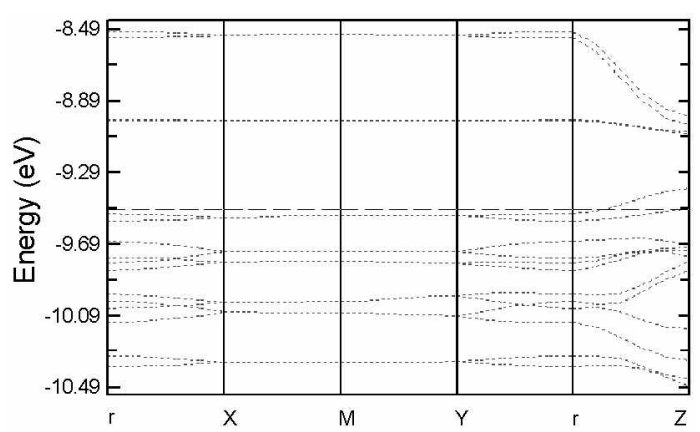

Fig. 6. Band structure of $\left[\mathrm{Os}_{4} \mathrm{C}_{9}\right]^{21-}$ sublattice. The dashed line at $c a .-9.49 \mathrm{eV}$ tefers to the Fenmi level.

$-11 \mathrm{eV}$. The Fermi level comes at slightly higher energy $(-9.49 \mathrm{eV})$, in a region of substantial Os-C antibonding. A generalization that seems to hold is that structures maximize bonding. Given that the bands at the Fenni level are $\mathrm{Os}-\mathrm{C}$ antibonding for $\mathrm{La}_{3} \mathrm{O}_{4} \mathrm{C}_{9}$. more stable strnictures should be formed on removing some electrons from the system. The $O$ s and $C$ contributions at the Fermi level are primarily due to the participation of the $O$ s and bridging $\mathrm{C}$ and to a lesser extent of the antibonding $1 \pi_{g}$ MOs. The position of the Fermi level cutting a rather narrow and sharp peak in the DOS indicates that $\mathrm{La}_{2} \mathrm{O}_{4} \mathrm{C}_{9}$ should be metallic.

A section of the band structure of $\left[\mathrm{O}_{4} \mathrm{C}_{9}\right]^{\hat{2}-}$ sublattice is shown in Figure 6 . The bands remain dispersionless in various directions of the reciprocal space. The Fenmi level, at $c a .-9.49 \mathrm{eV}$. crosses more dispersive bands along the crystallographic $c$ axis. allowing electrical conductivity along the $\left[\mathrm{Os}_{4} \mathrm{C}_{9}\right]^{3 /-}$ chain direction. Electrical resistivity measurements revealed a temperature dependence typical for a metal, ${ }^{l}$ in agreement with our electronic structure calculations.

\section{CONCLUDING REMARKS}

The electronic stnicture of $\left[\mathrm{O}_{4} \mathrm{C}_{9}\right]^{21-}$ presents us with highly covalent interactions of the transition metal with the unperturbed energy levels of the $\mathrm{C}$ atom and $\mathrm{C}_{2}$ units. Oxidation state formalism of $\left(\mathrm{La}^{3+}\right):\left(\mathrm{Os}^{(175+}\right)_{4}\left(\mathrm{C}_{2}^{-2}\right)_{2}\left(\mathrm{C}^{4}\right)_{5}$ for $\mathrm{La}_{-} \mathrm{O}_{4} \mathrm{C}_{3}$ constitutes a good starting point to describe its electronic structure. The formal charge of $\mathrm{C}^{+-}$is consistent with our calculations. Of course. this charge is reduced by covalent interactions with Os. For the $C_{z}$ unit, we find antibonding $1 \pi_{g}$ states occupied near the Fermi level. displaying a reduced triplebond character, and thereby causing the increase of the $\mathrm{C}-\mathrm{C}$ bond length. The bonding of the $\mathrm{C}_{2}$ units is characterized by strong $\mathrm{Os}-\mathrm{C}_{2}\left(3 \sigma_{\mathrm{g}}\right)$ and Os- $C_{2}\left(1 \pi_{g}\right)$ interactions. The Fermi level cuts a narrow and sharp peak in the DOS composed mainly of Os-C antibonding states and to a lesser extent of Os- $1 \pi_{s}$ bonding states. This allows us to conclude that the rather important occupation of the antibonding $\mathrm{l} \pi_{\mathrm{s}} \mathrm{MOs}$ and the depopulation of the bonding MOs, particularly the $3 \sigma_{8}$ one are responsible for the significantly weakened $\mathrm{C}-\mathrm{C}$ triple bond strength after interaction. According to the band structure, dispersive bands are observed along the polymeric $\left[\mathrm{Os}_{4} \mathrm{C}_{4}\right]^{2 l-}$ chain direction. This compound should be a ID-like metal.

Acknowledgments. This work was supported by the Kỵungsung Univerșity Research Grant in 2009 .

\section{REFERENCES}

1. Dashjav, E; Prots, Y; Kreiner G.; Schuelle, W: Wagner, F. R, Kniep, R. J. Solid State Chem. 2008, 181,3121 .

2. Dashjav, E; Kreiner, G.; Schuelle, W:; Wagner, F. R.: Jeitschko, W.: Kniep, R. J. Solid State Chem. 2007, 180,636 .

3. Kalnert, G. E.: Teitschko, W; Block; G. Z. Anorg. Allg. Chem. 1993, 619,442.

4. Hottmarn, R.-D.; Pottgen, R.; Jeitschko, W. J. Solid State Chem. 1992, 99, 134.

5. Pottgen, R.; Teitschko, W. Z. Voturforsch. b, 1992. 47,358 .

6. Gerdes, M. H.; Jeitschko, W.; Wachtmann, K. H.; Danebrock, M. E. J. Mater. Chem. 1997, 7, 2427.

7. Wachtmann, K. H.; Hufken, I; Jeitschko, W. $J$. Solid State Chem. 1997, 131, 49 .

8. (a) Hoftmann, R. J. Chem. Phys. 1963, 39, 1397. (b) Whangbo, M.-H.: Hoffmann, R. J. Am. Chem. Soc. $1978,100,6093$.

9. Pauling. L. The Natum of the Chemical Bond. Comell University Press: New York, 1960. 